\title{
La historiografía penitenciaria francesa después de Foucault: una aproximación a través de la obra de Jacques-Guy Petit (1975-2000) ${ }^{*}$
}

\author{
French prison historiography after Foucault: an approach via the works \\ of Jacques-Guy Petit (1975-2000)
}

\author{
Luis González Alvo \\ gonzalezalvo@gmail.com \\ Profesor \\ CONICET - Universidad Nacional de Tucumán \\ Bolívar, 800 - San Miguel de Tucumán \\ 4000 - Tucumán \\ Argentina
}

\begin{abstract}
Resumen
Hace cuarenta años, Vigilar y castigar marcó el comienzo de una "época dorada" de la historia de la prisión. Se estudiará la discusión que esa obra generó durante sus primeros años, tomando como objeto las principales reseñas y el debate titulado L'impossible prison. Luego, para realizar una aproximación a la historiografía posterior, se analizarán los aportes de Jacques-Guy Petit. Según algunos historiadores, la tesis doctoral de Petit adquirió un carácter de aporte "definitivo". Teniendo en cuenta esos aspectos, se intentará responder por qué los historiadores habrían dado una mayor valoración a la obra de Petit y por qué, sin embargo, no generó nuevos trabajos, sino fue seguida de una especie de declive que derivó en un desplazamiento del tema en la agenda historiográfica francesa.
\end{abstract}

\section{Palabras clave}

Historiografía francesa; Prisiones; Michel Foucault.

\begin{abstract}
Forty years ago, Discipline and Punish ushered in a "golden age" of historical studies on prison in France. This article will address the discussion on that work in its early years, by studying some of the leading reviews that were published at the time and the debate entitled L'impossible prison. Next, in order to approach the subsequent developments of prison historiography, it will examine the contributions of Jacques-Guy Petit. For some historians, Petit's doctoral thesis acquired a character of "definitive" contribution. Considering these aspects, this paper will attempt to answer why historians have laid a greater emphasis on Petit's work; and why, nonetheless, it did not result in new works, but was followed instead by a kind of decline that resulted in a topic shift in the French historiographical agenda.
\end{abstract}

\section{Keywords}

French historiography; Prisons; Michel Foucault.

Recibido el: $18 / 10 / 2014$

Aceptado el: 20/4/2015

\footnotetext{
${ }^{*}$ El presente trabajo, originado en el marco de la Beca de Iniciación en la Investigación (CIUNT, 2011-2012) fue terminado en el marco de la Beca Doctoral de CONICET (2014-2018). Agradezco la gentileza de Michelle Perrot por haberme recibido para entrevistarla sobre su participación en el auge de la historia de la prisión.
} 
El análisis histórico de la prisión, como es sabido, precede largamente a la intervención de Foucault. Sus orígenes pueden ubicarse en el campo de la sociología clásica. Primero en la obra de Durkheim (2001), donde los mecanismos, procesos y rituales de la penalidad constituyen la clave para el análisis de la sociedad, y luego en Weber (1964), quien elaboró una genealogía de la disciplina moderna entre el ejército y la fábrica. A partir de la década de 1930 la tradición marxista introdujo sustanciales aportes, buscando determinar cuál era el rol de los sistemas penales en las estrategias de dominio de clase y de qué maneras expresaba el poder estatal y el cambio histórico (GARLAND 1999, p. 39-106). ${ }^{1}$ Tal era, en términos generales, la situación de la historia del castigo penitenciario hacia la década de 1960, cuando furiosos motines comenzaron a hacer tambalear los pilares teóricos de la penalidad del primer mundo en medio de los años dorados del capitalismo.

En 1971, bajo el influjo de aquellos trabajos y de la grave crisis que atravesaban los sistemas penitenciarios occidentales, Rothman publicó The Discovery of the Asylum. Obra pionera, abordaba la historia de la prisión norteamericana rastreando una suerte de patrón cíclico de impulsos reformistas seguidos de procesos de paulatina "petrificación", derivados en ulteriores desplazamientos de los ideales originales por objetivos de organización más realistas (ROTHMAN 1971).

Pocos años después, Foucault (1975) y Deyon (1975) publicaron en Francia dos obras muy diferentes sobre la historia de la prisión. Mientras que Vigilar y castigar generaría enorme polémica, el trabajo de Deyon pasó, en relación a aquél, casi desapercibido. ${ }^{2}$ La obra de Foucault, además de producir debates interpretativos, funcionó -tal como su autor lo había deseado- como un formidable disparador para la multiplicación de los estudios sobre la cárcel y demás formas de disciplinamiento y castigo.

Mucho se ha dicho sobre Vigilar y castigar y no es el objeto de este escrito añadir un nuevo análisis de esta obra, sino observar el impacto que produjo entre los historiadores, para luego analizar el desarrollo posterior de la historiografía penitenciaria francesa. ${ }^{3}$ Con tal objetivo, en este trabajo se abordará, en primer lugar, la discusión que la obra generó en los primeros años, empleando algunas de las principales reseñas que se publicaron en la época, y el debate entre "el filósofo y los historiadores" coordinado y publicado por Michelle Perrot bajo el título de L'impossible prison (1980).

\footnotetext{
${ }^{1}$ Garland sostiene que es posible diferenciar dos corrientes de interpretaciones marxistas. Una representada en la obra de Rusche y Kirchheimer y Melossi y Pavarini quienes se abocan a demostrar la interrelación entre las instituciones penitenciarias y los modos de producción, entendiendo el castigo como un fenómeno económico supeditado al mercado laboral. La otra corriente, representada por los trabajos de Pashukanis, Hay e Ignatieff, enfatiza el papel político del castigo en la lucha de clases y en el monopolio del poder del Estado, como instituciones ideológicas legitimadoras del predominio de clase (GARLAND 1999).

2 André Zysberg, en una reseña simultánea de ambos libros, caracteriza al trabajo de Deyon como "un corto ensayo (acompañado de una juiciosa antología de la prisión) donde se ajusta a mostrar, más allá de 1789, la persistencia de las mismas obsesiones punitivas" (ZYSBERG 1976, p. 169). A diferencia de Foucault, Deyon se enfocaría más en las continuidades.

3 Al hablar de "historiografía penitenciaria" en este artículo nos referimos exclusivamente a los trabajos historiográficos centrados en el nacimiento de la penitenciaría, entendida -como lo hacían sus contemporáneoscomo el lugar de "tratamiento" de penados varones, sanos y mayores de edad. No abordaremos, por consiguiente, estudios sobre otros tipos de prisiones o formas de confinamiento tales como los asilos de menores o enfermos mentales, las casas correccionales de mujeres, etc.
} 
En segundo lugar, para realizar una aproximación al desarrollo de la historiografía penitenciaria, estudiaremos los aportes de Jacques-Guy Petit, el principal historiador de la prisión francesa en tiempos posfoucaultianos. Debe señalarse que Ces peines obscures -la tesis doctoral de Petit- fue considerada por algunos historiadores como una superación de Vigilar y castigar, y rápidamente adquirió un carácter de aporte "definitivo" (MARAIS 1990, p. 547). Ahora bien, esa característica pudo haber producido una especie de cierre del tema, punto sobre el que volveremos al final de este trabajo. Hasta fines del siglo XX continuaron produciéndose investigaciones sobre otros aspectos de la historia de las instituciones de confinamiento francesas (sobre el tratamiento de los menores, de las mujeres, aspectos de la vida cotidiana, etc.). Sin embargo, el espacio editorial continuó restringiéndose, y las publicaciones redujeron su ámbito casi exclusivamente a las editoriales universitarias. En el viraje al siglo XXI, los abordajes sociológicos tomaron el relevo del lugar privilegiado que el análisis histórico de la cárcel había ostentado desde 1975. En el ámbito académico francés actual, al conversar con Michelle Perrot, Philippe Robert o Eric Pierre, ${ }^{4}$ se obtiene la impresión de que la historia de las prisiones hubiera pasado a retiro en los últimos cuatro o cinco años, junto a las generaciones de Perrot y Petit.

Por último, teniendo en cuenta esos aspectos, se intentará responder por qué los historiadores habrían dado una mayor valoración a la obra de Petit en relación a Vigilar y castigar y por qué, sin embargo, ésta no habría generado nuevos trabajos, sino que fue seguida del declive del tema en la agenda historiográfica francesa.

\section{Después de Vigilar y castigar, primeras reseñas y comienzo de un diálogo}

Entre las recensiones más favorables de Vigilary castigar cabe mencionar la que publicó en la revista Annales André Zysberg, por entonces un joven doctorando en historia. Allí se lo describe como un libro denso, repleto de referencias bibliográficas sobre la genealogía de la prisión. Sumamente elogioso, sólo se permite una crítica respecto a la descripción que el autor realiza sobre los bagnes, especie de presidios franceses, objeto de la tesis doctoral de Zysberg. ${ }^{5}$ En su argumentación, sostiene que Foucault se apresura en caracterizarlos como una forma a la vez rigurosa y lejana de encarcelamiento cuando, por el contrario, muestra una anatomía muy distinta a la penitenciaría y constituye casi un "antipanóptico" donde sobreviven prácticas del siglo XVI (ZYSBERG 1976, p. 173).

\footnotetext{
${ }^{4}$ Eric Pierre, historiador especializado en las instituciones para menores, es uno de los discípulos de Petit y su sucesor en la cátedra de "Historia de los mundos contemporáneos" en la Universidad de Angers. En este trabajo se han empleado tres entrevistas personales realizadas a Michelle Perrot, Philippe Robert y Eric Pierre entre noviembre y diciembre de 2012.

${ }^{5}$ El término francés bagne es normalmente traducido como presidio en castellano aunque no es un término exactamente homólogo. Etimológicamente, son completamente diferentes. Bagne comenzó a emplearse en el siglo XVII, proveniente del término italiano bagno, aplicado a un tipo de prisiones asentadas en antiguos baños públicos. En un comienzo los bagnes se emplearon para encerrar esclavos hasta que, con la desaparición de la condena a galeras, pasó a ser un establecimiento de trabajos forzados casi siempre portuarios. Los bagnes continentales más importantes fueron los de Brest y Toulon mientras que en las colonias fueron los de Cayena y de Nueva Caledonia. El término presidio, por otra parte, deriva del latín, y en sus orígenes designaba una fortaleza militar, y con ese sentido se mantuvo en la historia colonial hispánica.
} 
Al año siguiente, Jean-Paul Brodeur, criminólogo canadiense, publicó una reseña en la revista Criminologie. Su análisis pone el acento en temas que tienen un interés inmediato para el criminólogo "ya sea porque convergen con la investigación criminológica o porque constituyen un modo de crítica" (BRODEUR 1976 , p. 196). Si bien puede considerársela como una reseña elogiosa, es más aguda que la de Zysberg en sus opiniones sobre las hipótesis y la metodología. Brodeur comienza por distinguir una "tesis histórica", según la cual, en el pasaje del suplicio a la penalidad moderna, el castigo del alma propuesto por los juristas fue "colonizado" por una tecnología de los cuerpos del sistema carcelario. Es la piedra angular del libro. La segunda tesis, que llama "sociológica" es que la prisión constituye una pieza esencial de una gestión política de los ilegalismos. ${ }^{6}$ Su rol es crear una delincuencia políticamente inofensiva, constituida de individuos fácilmente reconocibles, ya que portan los estigmas de su pasaje por la prisión. La tercera tesis, "epistemológica", es la decisión metodológica de articular las estructuras que definen el poder y el saber sobre un horizonte de efectos de reforzamiento recíproco. La genealogía del complejo político-científico, donde saber y poder se legitiman y retroalimentan mutuamente.

Si bien la reseña es un esfuerzo interpretativo dirigido a emplear la obra para los estudios criminológicos, Brodeur desliza, sobre el final, algunas críticas al método. La principal crítica se refiere al uso de fuentes, ya que en Vigilar y castigar se emplean más fuentes externas a las prisiones (libros de juristas, la prensa, etc.) que documentos generados en ellas (informes, estadísticas, libros de cuentas, etc.). Brodeur se pregunta si hacer la historia del plan intencional sobre el que se apoya el nacimiento de la prisión equivale a hacer la historia del nacimiento de la prisión. Sea cual fuera la respuesta, concluye, debe considerarse que al libro le falta una base empírica. Por último, respecto al empleo del panóptico de Bentham (sus planos aparecen reproducidos sobre el final del libro), sostiene que da la apariencia de ser un "hermano de nuestras prisiones". Sin embargo se pregunta si debemos concluir que existió una influencia efectiva del panóptico en el sistema carcelario. En una analogía un tanto punzante, Brodeur argumenta que Da Vinci dibujó con gran precisión aviones y helicópteros, sin embargo su papel en el desarrollo de la aeronáutica puede considerarse insignificante (BRODEUR 1976, p. 216).

Un año más tarde, en 1977, Jacques Léonard publicó una recensión en los Annales historiques de la Révolution française. Fue la más resonante de todas ya que encarnó lo que podría denominarse la "reacción" historiográfica. Foucault decidió responder a través de un artículo titulado "El polvo y la nube". Ese intercambio entre Foucault y Léonard, motivó a Michelle Perrot, una de las pioneras del estudio social de las prisiones en Francia, ${ }^{7}$ a convocar una mesa redonda para discutir Vigilar y castigar junto a su autor y a un grupo de

\footnotetext{
${ }^{6}$ Sobre esta segunda tesis, como se verá en el penúltimo apartado, se erigirá parte importante de la estructura argumentativa de Ces peines obscures. También se observan reflexiones inspiradas en las otras dos, aunque más matizadas.

7 En 1973, en un coloquio sobre delincuencia y exclusión social, presentó una comunicación, titulada "Délinquance et système pénitentiaire en France au XIXe siècle" que luego sería publicada como un artículo en la revista Annales (PERROT 1975, p. 67-91).
} 
reconocidos historiadores. El resultado del debate fue publicado bajo el título de La prisión imposible. Investigaciones sobre el sistema penitenciario en el siglo XIX, reunidas por Michelle Perrot. Debate con Michel Foucault. ${ }^{8}$ Junto a la discusión, se incluyó la reseña de Léonard, la respuesta de Foucault y una serie de artículos sobre la prisión de otros autores.

El prólogo a la obra fue encargado a Maurice Agulhon, en su carácter de presidente de la Sociedad de historia de la revolución de 1848 y portavoz del grupo de autores de la serie de trabajos incluidos en el libro. Si bien Agulhon, como veremos más adelante, fue un severo crítico del trabajo de Foucault reconoció el carácter impulsor de su estudio. Al preguntarse el por qué de este auge de la historia de las cárceles, sostiene que, fuera de los motivos más o menos subjetivos o contingentes, más o menos inspiradas en tal o cual movimiento social, existía en primer lugar una razón historiográfica, más grande y evidente que cualquier otra. La renovación historiográfica francesa había abierto muchos nuevos temas de investigación sin embargo, hasta Michel Foucault, nadie había reorientado con tanto vigor la historia hacia las prisiones (PERROT 1980, p. 5).

\section{Jacques Léonard y la "reacción" historiográfica}

Léonard comienza su reseña sosteniendo que no era la primera vez que un filósofo "sembraba ideas en el campo de los historiadores suscitando reacciones e investigaciones". Si nos detenemos un segundo en esa oración -aparente formalidad o una simple gentileza- veremos al proseguir con el desarrollo de la reseña que se trata de una declaración de guerra. En la batalla, Léonard se situará del lado de los historiadores, cuyos campos han sido "devastados" y no "sembrados con ideas". Si Foucault encarna una "revolución", Léonard no tiene problemas en denominar a su respuesta como una "reacción".

Su reacción surge, en primer lugar, ante la rapidez fulgurante del análisis de Foucault, quien "recorre tres siglos a rienda suelta, como un caballero bárbaro que incendia la estepa sin precaución" (PERROT 1980, p. 11). El historiador no puede hacer esta economía de verificaciones sociológicas y cronológicas. Se admite el género sintético del ensayo, que se basa en trabajos anteriores sin aparato crítico justificativo o el género hipotético del artículo metodológico o del panfleto que adelanta una interpretación brillante, a verificar ulteriormente con profundos estudios. Pero entre todas estas opciones no cabe "devorar campos poco cultivados", como lo eran la historia de las prisiones o de la medicina y los hospitales (que es el campo de estudios de Léonard).

Segunda reacción: Vigilar y Castigar dejará insatisfechos a los especialistas de los siglos XVIII y XIX porque no establece un diálogo con ellos. Aunque algunos son extensamente citados, ${ }^{9}$ los estudiosos del período revolucionario se preguntarán el por qué de la ausencia de la toma de la Bastilla y el ataque a las prisiones de provincias, la experiencia de los jueces electos, las masacres de

\footnotetext{
${ }_{8}^{8}$ El título original en francés es L'Impossible prison. Recherches sur le système pénitentiaire au XIXe siècle, réunies par Michelle Perrot. Débat avec Michel Foucault (PERROT 1980). Fue publicado parcialmente en español en 1982 (LEONARD; FOUCAULT 1982).

${ }^{9}$ Los más citados son Pierre Chaunu, Emmanuel Le Roy Ladurie, Denis Richet e Yves Marie Bercé.
} 
septiembre, los tribunales revolucionarios, la "santa guillotina", la repugnancia que suscitaron los espectáculos públicos del Terror y que contribuirá en buena medida al triunfo del encarcelamiento como solución punitiva discreta. Estas ausencias impiden comprender por qué los revolucionarios no quisieron una prisión "para castigarlo todo".

La tercera reacción, cuyas raíces se sumergen en la historia institucional de las prisiones, se produce ante la ausencia de una suerte de cronología legislativa. Como ejemplo, Léonard sostiene que si bien la Asamblea Constituyente abolió antiguas tradiciones penales y optó por la privación de la libertad, el Código Penal de 1810 (que perfeccionó el sistema de prisiones) restableció antiguos castigos humillantes como la exposición pública, el cepo, las marcas corporales, la amputación de la mano, contradicciones que se esperaría que Vigilar y castigar clarificara. Asimismo, en la parte del libro correspondiente al siglo XIX (al que sólo se le dedica las últimas setenta páginas) falta también una mínima cronología jurídica: la Restauración de 1814 intentó mejorar las condiciones materiales de las cárceles, la Monarquía de Julio suprimió en 1832 el cepo, las marcas corporales, las amputaciones, y por ley instituyó la noción de circunstancias atenuantes que contribuyeron a reducir las penas capitales a la mitad en pocos años. El gobierno provisorio de 1848 abandonó la pena de muerte en materia política, profundizó la "humanización" del derecho penal suprimiendo las exposiciones públicas y aumentó las experiencias de "mejoramiento moral" de los prisioneros, conservando el aislamiento pero suprimiendo temporalmente los trabajos forzados. En este punto, Léonard sostiene -algo que Zysberg había anticipado- que Foucault no menciona los bagnes ni su extinción. Cabría agregar al análisis de Léonard que tampoco se termina de explicar las razones de la pervivencia de la pena de muerte que, en Francia, subsistirá hasta 1981. La última ejecución por la guillotina se aplicó en Marsella en 1977, dos años después de la publicación de Vigilar y Castigar. ${ }^{10}$

La cuarta crítica, cuyas raíces Léonard sitúa en las historias especializadas (de la medicina, de la educación, etc.), aunque también podría pensarse en la teoría de la resistencia cotidiana de James Scott, es que Foucault exagera la racionalización y normalización de la sociedad francesa, minimiza la resistencia de hábitos del pasado y subestima la importancia del desorden. Como ejemplos, el historiador del trabajo le recordará la prolongada supervivencia de las actividades artesanales frente a la organización industrial; el historiador de los asuntos militares evocará la persistencia de las insubordinaciones y la impotencia de las ordenanzas militares; el historiador de la enseñanza le objetará la diversidad de tipos de escuelas, las improvisaciones locales, las constantes faltas de los alumnos, la confusión de las edades, el empleo del tiempo. Léonard mismo, como historiador de la medicina, señala que los reglamentos de los hospitales no deben tomarse al pie de la letra, y que en su época eran siempre

\footnotetext{
${ }_{10}$ Entre la tercera y la cuarta crítica, Léonard agrega que Vigilar y castigar no se apoya en estadísticas, tipologías de crímenes y delitos, clases de prisioneros (políticos, obreros, militares, prostitutas, condenados de derecho común, acusados). No hay tampoco análisis sociológicos respecto a magistrados y abogados. Todas estas observaciones, como veremos, serán tenidas en cuenta por Jacques-Guy Petit (1990).
} 
ridiculizados por su inobservancia y desorden en periódicos y revistas médicas. Se podría, concluye, "continuar durante largo rato levantando el polvo de los hechos concretos en contra de la tesis de la normalización masiva" (PERROT 1980 , p. 12). ${ }^{11}$

Las últimas críticas son las referentes al método, ya que sostiene que no se desprende completamente de la lectura si su objetivo es describir una maquinaria o denunciar una maquinación y esa confusión puede deberse al exceso que el autor hace de verbos pronominales o reflexivos, del pronombre personal "se" y de analogías. Respecto al poder disciplinario, señala que Foucault no clarifica quién es el dueño de ese poder. De allí que la explicación se vuelva mecanicista, hay una maquinaria sin mecánico, el poder tiene su principio menos en una persona que en cierta distribución concertada de los cuerpos, las superficies, las luces, las miradas. Hay una maquinaria, sostiene Léonard, pero poco importa quien ejerce el poder y, a medida que Vigilar y Castigar avanza, esta interpretación mecanicista del sistema carcelario se diluye en una "operación política", cuyos responsables siguen sin aparecer y se pregunta quiénes son: ¿la policía, las autoridades judiciales o penitenciarias, la burguesía, la clase dirigente? Concluye que Foucault esquiva la respuesta y, aunque sugiera que serían los "grupos dominantes", surge la pregunta sobre quiénes conforman esos grupos.

\section{El "juicio" de los historiadores y el "descargo" del filósofo}

El 20 de mayo de 1978 se llevó a cabo una mesa redonda para discutir los textos del debate Foucault-Léonard. Además de los dos autores, participaron Maurice Agulhon, Nicole Castan, Catherine Duprat, François Ewald, Arlette Farge, Alexandre Fontana, Carlo Guinzburg, Remi Gossez, Pascal Pasquino, Michelle Perrot y Jacques Revel. Foucault le confesaría más tarde a Perrot que aquel día había tenido la sensación de estar compareciendo ante sus jueces.

En primer lugar se le preguntó dónde radicaba la importancia del nacimiento de la prisión y su acelerada difusión a comienzos del siglo XIX y si no estaba exagerada la relevancia de la prisión en la penalidad, puesto que subsisten durante todo el siglo XIX otros modos de castigar (muerte, bagnes, deportación). Otros interrogantes fueron si rehuía de explicaciones estructurales o sociales para privilegiar un proceso "acontecimental" o si había en Vigilar y Castigar una oscilación entre un hiperracionalismo y una subracionalidad (PERROT 1980, p. 40-46).

En su descargo, Foucault no respondió directamente y en orden a cada pregunta. Ensayó una respuesta globalizadora según la cual habría tomado la prisión para explicar la penalidad, porque hasta entonces había sido descuidada por la historiografía y con el objeto de retomar el tema de la genealogía de la moral siguiendo las transformaciones de las "tecnologías morales". A todo ello

\footnotetext{
${ }_{11}$ De la misma manera, el mismo símbolo del Panóptico, monumento de la vigilancia racional, merecería ser atenuado. Hasta el propio Foucault admite, dice Léonard, que tal proyecto ha sido poco concretado ya que muchas prisiones francesas del siglo XIX eran viejos edificios medievales y aquellas que fueron construidas luego de 1830 generalmente no respondían a la concepción de Bentham. Asimismo, si muchas escuelas, cuarteles, hospitales y prisiones se asemejan entre sí es porque ocuparon con frecuencia edificios conventuales secularizados por la Revolución. En este sentido, continúa Léonard, también sorprende que Foucault no insista con mayor claridad respecto a la herencia religiosa de la empresa de amaestramiento del cuerpo que pretende describir.
} 
se sumó también un hecho de actualidad ya que en el momento que escribió el libro, la prisión y las prácticas penales estaban siendo cuestionadas tanto en Francia como en Estados Unidos, Inglaterra e Italia, entre otros países.

El autor de Vigilary castigar sostuvo que intentó hacer una "eventualización", 12 aunque el evento como unidad de análisis haya sido poco apreciada por los historiadores desde los últimos tiempos. Eventualizar sería, en primer lugar, una ruptura de lo evidente: allí donde se veía una constante histórica se trata de buscar una singularidad. Mostrar que encerrar a los delincuentes no era la única cosa que podía hacerse con ellos. La eventualización consiste además en encontrar las conexiones, los encuentros, los apoyos, los bloques, las relaciones de fuerza que han formado esas "evidencias" y "necesidades". Estudiar la encarcelación penal como un "evento" y no como un hecho institucional, argumentaba, equivale a definir los procesos de inserción progresiva en las formas de punición legal de las prácticas precedentes de encierro y el movimiento mediante el cual el encarcelamiento se convirtió, como forma de castigo y como técnica de corrección, en pieza central de la penalidad.

Respecto al "exceso de atención" dada en Vigilar y castigar a los reglamentos y proyectos de la época, el autor reconocía que el Panóptico no es una buena descripción de la "vida real" de las prisiones del siglo XIX. Sin embargo, no quería describir la vida real de las prisiones, sino otra cosa y Bentham le servía para eso. Es una programación de comportamiento y no un proyecto de realidad que fracasa. Es un fragmento de realidad que induce efectos en lo real tan específicos como la división entre verdadero y falso en la manera en que los hombres se conducen. Sobre la finalidad de su trabajo, Foucault responde que intentó ayudar de alguna manera a resquebrajar algunos lugares comunes sobre la locura y la normalidad, sobre la delincuencia y el castigo. Su meta fue contribuir a que determinadas frases ya no pudieran ser dichas con la misma facilidad, desnaturalizar puntos de vista largamente difundidos (PERROT 1980, p. 52).

Finalmente, La prisión imposible se cierra con dos epílogos, a cargo de Agulhon y Foucault. Agulhon concluye que, a comienzos de la década de 1980, la reflexión sobre la historia de la cárcel estaba más abierta que nunca. Estado en el que probablemente continúa en nuestros días ya que unos quince años más tarde fue prácticamente abandonada salvo por la notable excepción de Petit -a quien nos dedicaremos en el próximo apartado- y un pequeño grupo de historiadores ligados a él y a Michelle Perrot. ${ }^{13}$ Esto produjo una sensación de que el tema hubiera "pasado de moda", asunto al que retornaremos en las reflexiones finales. ${ }^{14}$

\footnotetext{
12 "Eventualización" y "eventualizar" son las palabras escogidas por el traductor Jordá para dos neologismos de Foucault: "événementialiser" y "événementisation". Aunque creemos que es más adecuada la traducción de "événement" por "acontecimiento" y no "evento", las palabras "eventualización" y "eventualizar" son un poco menos cacofónicas -aunque tampoco demasiado- que "acontecimientación" y "acontecimentar".

${ }_{13}$ Cabe mencionar en particular el coloquio realizado en Fontevraud en 1982, organizado por Michelle Perrot, Alain Corbin y Petit, que dio a luz la obra colectiva La Prison, le bagne et l'histoire (PETIT 1984). Fue también relevante el seminario de Robert Badinter en I'EHESS sobre las prisiones desde fines del siglo XIX (1986).

${ }^{14}$ Es sumamente descriptivo el hecho de que el traductor de la edición española -reducida en comparación con la francesa-sostuviera en 1982 que el debate sobre la historia penitenciaria ya no gozaba "del favor [editorial] de que disfrutó unos pocos años atrás" (LEONARD; FOUCAULT 1982, p. 81).
} 
Agulhon culmina su epílogo argumentando que, por mucho tiempo, el siglo XIX francés fue visto como una época de conquista progresiva de la libertad mediante la puesta en práctica de los principios de la Ilustración. El socialismo criticó esa idea autosatisfactoria señalando la crudeza del naciente capitalismo decimonónico. Ahora, por 1975, una nueva oleada ataca directamente el racionalismo y Foucault ocupa un lugar de importancia allí. Excesivamente emprendedor, el racionalismo comprometió las ideas filantrópicas e insertó el marco conceptual de la clasificación en los reglamentos de internado y de encierro. Es ese impulso el que lleva a Foucault a privilegiar el Panóptico de Bentham, donde el máximo de vigilancia se une al máximo de racionalización. De ahí procede la "extrapolación impresionante" que realiza al entender al racionalismo liberal como una prefiguración de una sociedad totalitaria. Agulhon concluye que el siglo XIX sí experimentó una suerte de progreso en los métodos punitivos.

Partiendo de esa última afirmación, Foucault se pregunta si el coche celular es una forma más humana que la tradicional cadena de forzados. Dice que suponer eso es simplificar la realidad histórica y la tarea del historiador. Asimismo, sostiene que la tesis que Agulhon critica no le pertenece. No reconoce en absoluto haber criticado el racionalismo, es más, afirma que bastante esfuerzo le ha costado al racionalismo reponerse de los elogios que sufrió por parte de los marxistas ortodoxos en los ' 50 . Añade que ha intentado mostrar las formas de racionalidad realizadas en algunas prácticas institucionales, administrativas, judiciales, médicas, etc. Ver en ese análisis una crítica de la razón en general sería postular que de ella sólo puede venir el bien y que el mal sólo puede venir de su rechazo. Asimismo, sostiene finalmente, que el respeto del racionalismo como ideal no debe constituir un chantaje para impedir el análisis de su puesta en práctica en la realidad (PERROT 1980, p. 317).

\section{Jacques-Guy Petit: el camino de un historiador hacia la prisión}

En 1975, año de publicación de Vigilar y castigar, Petit cumplía 37 años. Tenía entonces una considerable carrera académica a sus espaldas, aunque no dedicada a la historia de la prisión sino al pensamiento religioso. Nacido en Angulema, en el centro-oeste de Francia, Petit cursó estudios superiores en el Instituto Católico de Toulouse, donde obtuvo las licenciaturas en Teología y en Filosofía.

Mientras realizaba estos primeros estudios, su interés por la vida y el pensamiento del abate Jules Monchanin lo fueron conduciendo a la investigación histórica, particularmente de los siglos XIX y comienzos del XX. De esa manera, desde 1966 prosiguió sus estudios en la Universidad de Paris X, donde obtuvo el grado de magister en historia contemporánea. Ya inmerso en el mundo de los historiadores, su itinerario formativo incluirá otras tres universidades: Toulouse, Angers y La Sorbona. Por esos años publica sus primeros artículos sobre el pensamiento del pastor Dietrich Bonhoeffer y Monchanin (PETIT 1969; 1970a; 1970b) y, en 1972, una vez graduado de magister en Paris X, comienza a trabajar en la Universidad de Angers como profesor asistente de Historia 
Contemporánea. ${ }^{15}$ Dos años más tarde, bajo la dirección de René Rémond, Petit finaliza su tesis (Ilamada de tercer ciclo en el sistema educativo francés de la época) con la que obtendrá el título de doctor en historia por la Universidad de Paris X (PETIT 1983). Culminaba así su primera etapa de investigaciones sobre el pensamiento religioso francés.

Por entonces un notable cambio había comenzado a operar sobre los intereses historiográficos de Petit. En sus estadías parisinas se relacionó con Michelle Perrot, quien, junto a Foucault, era una de las pioneras en el estudio sociohistórico de las prisiones. Surge así la ambiciosa idea de realizar una tesis doctoral de Estado que, tomando como punto de partida la discusión en torno a Vigilar y castigar, contrastara sus hipótesis con un denso trabajo de fuentes a nivel nacional y llenara las lagunas historiográficas que le habían señalado a Foucault críticos como Léonard o Zysberg. Se trataba de una enorme empresa que, aún con el viento a favor del auge de la historia de las prisiones generado por la obra de Foucault, demandaría diez años de trabajo, incluido medio año sabático que le otorgara la Universidad de Angers.

Los años que van entre 1975 y 1990 pueden ser llamados "años dorados" de la historia de la prisión francesa. En los primeros cinco años que siguen a la publicación de Vigilar y castigar (1975-1980) se forman las bases del auge: se multiplican las reseñas del libro, se publicita fuera de los medios académicos a través de los periódicos, se forman grupos de estudio que cristalizan en nuevas tesis, son años de ampliación del espacio editorial. Esos años de inicial efervescencia culminan con la publicación de La prisión imposible, que deja asentadas en una obra colectiva las críticas de los historiadores y abre el camino hacia una superación del aporte de Foucault. A partir de entonces, jóvenes tesistas como Petit, se dedican a profundizar y completar las vetas inexploradas de la historia de las prisiones, temas considerados de primer orden por la agenda investigativa francesa de la década de $1980 .{ }^{16}$

Con el paso de los años, Jacques-Guy Petit se convirtió en el principal referente de los estudios sobre la historia de la prisión en Francia. Entre 1981 y 1988 publicó numerosos artículos sobre el tema, colaboró con obras colectivas en Holanda e Italia, organizó encuentros científicos y dirigió un trabajo colectivo que reunía a los principales investigadores sobre espacios de confinamiento franceses (PETIT 1984).

En 1981 Petit publica un primer avance de su investigación, bajo la forma de un estado de la cuestión sobre la historia de las cárceles. En su marco teórico, Petit enuncia a los precursores de la historia penitenciaria anteriores a Foucault: Chaunu, Agulhon, Le Roy Ladurie, Deyon, Perrot y Zysberg. Respecto a Vigilar y castigar, sostiene que no estudia tanto la institución penitenciaria como la genealogía y el discurso de la razón punitiva y el proceso por el cual el "castigo corrector" de la prisión devienen claves de la penalidad (PETIT 1981, p. 365).

\footnotetext{
15 Petit se desempeñará como profesor universitario en Angers hasta su jubilación en 2006. Continúa relacionado con la universidad en su carácter de profesor emérito.

${ }^{16}$ Ejemplo de ello es el premio que el parlamento francés otorga a Petit tras la publicación de Ces peines obscures (Prix de la recherche historique de l'Assemblée Nationale, 1990)
} 
En cuanto a los estudios posteriores a Foucault, destaca que la mayoría han conseguido escapar del dilema planteado por Leonard: el de la verificación laboriosa de las orientaciones generales de Vigilar y castigar o la refutación puntillosa de sus tesis. Entre los aportes más significativos menciona a Castan, Duprat, Vallete, Lebrun y algunos autores que investigaban el tema con anterioridad como Zysberg y Perrot. Aquellos estudios complementaban el libro de Foucault al mismo tiempo que, conocedores de los archivos nacionales, departamentales o religiosos, aportaban más pistas para identificar aspectos de las cárceles que aún necesitaban ser clarificados y profundizados. Petit comienza de esa manera a perfilar su ambición investigativa.

Si en la primera mitad del siglo XIX, proliferan los discursos humanistas sobre la reforma de las prisiones, en la práctica, como ya había señalado Perrot, los cambios son generalmente discretas. Al leer los reglamentos u otros documentos de las prisiones y contrastarlos con fuentes provenientes de distintas oficinas ministeriales, correspondencias oficiales, informes de la administración penitenciaria, se observa que las estrategias de formación de hombres laboriosos fueron en gran medida inciertas y contradictorias. Su meta será, a partir de entonces, estudiar la evolución del sistema penitenciario a la luz del análisis de prácticas concretas de encierro según los regímenes laborales y productivos, a través de las diferentes etapas políticas y en relación con los hombres que habitan la prisión como los que la ven desde afuera.

Su primer trabajo publicado en esta dirección abordaba el espacio carcelario reformado en el siglo XIX como sistema utópico de los arquitectos reformadores y como un espacio real, donde las representaciones y lo vivido juegan un papel central. Describe las razones del fracaso del sistema celular y la adopción final de principios de organización colectiva. Su tesis principal es que el espacio individualizado se muestra rápidamente ineficaz (los contemporáneos observan cómo deteriora las mentes de los internos) y antieconómico. Sin embargo, añade, los planos de prisiones celulares continuarán proliferando hasta el siglo XX, demostrando las numerosas incoherencias del sistema penitenciario que sólo un estudio de carácter general podría ayudar a clarificar (PETIT 1984, p. 165).

\section{En la cresta de la ola: Ces peines obscures y los historiadores}

En la época en que Petit ya destacaba como conductor de aquel grupo de historiadores de la prisión, Michael Ignatieff distinguía tres corrientes en la historia de las prisiones francesa. Una primera línea de análisis hacía de la penalidad una historia del Estado moderno luchando por afirmarse contra la criminalidad y el desorden. La segunda corriente veía en la prisión una manifestación de la lucha de clases, la función social de la institución y su régimen dependían de las necesidades de las clases dominantes que deseaban instaurar el sistema capitalista. Una tercera línea, que no necesariamente se apartaba totalmente de la segunda, abordaba el sistema penitenciario como un componente de "racionalidad modernizante" (IGNATIEFF 1984, p. 10).

Dicho de un modo aún más simplificado - pero bastante difundido- la historiografía de las cárceles se dividiría entre un tipo de análisis "utilitario" y 
otro "intencionalista", inaugurado en Francia por Vigilar y castigar. En aquella corriente, aunque separada por un abismo metodológico, puede situarse la tesis doctoral de Jacques-Guy Petit publicada en 1990 bajo el título Ces peines obscures. La prison pénale en France, 1780-1875. Orientado por Michelle Perrot, Petit se valió tanto del trabajo de Foucault como de sus críticos para realizar una tesis doctoral de carácter monumental: diez años de trabajo y 1411 páginas de resultado. ${ }^{17}$ Ces peines obscures venía a ampliar el trabajo de Foucault mediante su enfoque y su metodología.

En Vigilar y castigar la penitenciaría aparece como institución modelo de una sociedad que, además de castigar a los transgresores, intentaba crear e implementar una nueva práctica social disciplinaria. No conforme con esa explicación, Petit insiste en la importancia del contexto de aquella lenta transformación del sistema punitivo y observa menos una organización metódica y racional que el resultado pragmático -y en muchas ocasiones contradictoriode la puesta en práctica de la utopía penal de la Ilustración, truncada por el surgimiento de la cuestión social, punto en el cual Petit hace hincapié para señalar la importancia de la dimensión económica, en la cual el trabajo al interior de las prisiones constituye el componente principal (DHAUSSY 2005, p. 575).

La nueva prisión francesa no es fruto únicamente del racionalismo triunfante, aspecto que -según Petit- Foucault ha exagerado, sino que pertenece también a la esfera del misticismo, del prerromanticismo, como lo sugieren las prisiones imaginarias de Piranesi. Así como Foucault abreva fundamentalmente en la genealogía disciplinaria de Weber, Petit lo hace en aspectos atávicos de la penalidad señalados por Durkheim. Desde un punto de vista metodológico, Petit señala que Foucault no analiza los debates de 1789-1791, ni los códigos correccionales o penales sino que realiza un análisis centrado en la reunión de elementos dispersos de los reformadores del siglo XVIII en un todo coherente pero algo alejado a la realidad pos revolucionaria (PETIT 1990, p. 71).

Jean-Luc Marais, en una reseña publicada en la revista Annales de Bretagne et des pays de l'Ouest, es tan breve como elogioso. Sostiene que si bien existe un gran riesgo al declarar que un libro es definitivo, esa es, sin embargo, la impresión que experimenta el lector de la tesis Petit (MARAIS 1990, p. 547). Probablemente esa sensación se deba a los objetivos de la obra, cuya intención es precisamente hacer una historia total de la reforma penitenciaría francesa. Ces peines obscures, describe a nivel nacional -en un enorme esfuerzo heurístico- la puesta en práctica de la prisión penal, es decir, el pasaje de la prisión preventiva a la prisión como pena. La riqueza del libro reside en superar el análisis discursivo, analizando también las fuentes producidas en las penitenciarías para estudiar las causas materiales de lo que Petit denomina fracaso del encarcelamiento celular (PETIT 1990, p. 548). De esa manera el análisis de Petit se hace más denso y le permite demostrar que no existió un frente unido de la burguesía sino diversos grupos de acción. En ese sentido analiza los papeles cumplidos por el fragmentado grupo de

\footnotetext{
${ }_{17}$ Para su publicación por la editorial Fayard el trabajo fue reducido a 749 páginas.
} 
los filántropos, las hesitaciones de la administración (siempre necesitada de fondos), el papel del gobierno (siempre reticente para otorgar los fondos) y los emprendedores privados relacionados al trabajo de los prisioneros.

Además del reconocimiento de Marais, Ces peines obscures recibió la aprobación del otrora líder de la "reacción" historiográfica Jacques Léonard, quien señaló que Petit llenaba las lagunas que, a fines de los '70 se le habían marcado a Foucault. Lo consigue al desmenuzar para su análisis el complejo proceso de transición de la cárcel de Antiguo Régimen hasta el régimen celular (fracasado) a fines del siglo XIX. Demuestra con su investigación la relación íntima y necesaria entre historia social e historia penitenciaria, ya que tanto la prisión como el bagne expresan la naturaleza de las relaciones entre los que están dentro y los que están fuera de aquellas instituciones. Una vez más se acentúa la deuda teórica con Durkheim y la visión social producida desde el exterior de la prisión. En la obra de Petit queda demostrado de qué manera el mejoramiento de la suerte de los detenidos no progresará sino lentamente:

[...] la opinión pública juzgará indecente brindar a 'culpables' el bienestar y el confort que no tienen los soldados en sus barracas o los trabajadores honestos en su modestas casas. Así como la condición de los proletarios es lamentable, parecería incongruente preocuparse demasiado de la suerte de los malhechores (LÉONARD 1985, p. 227).

Otro fuerte de Ces peines obscures es desarrollar la dimensión cotidiana para comprender la realidad carcelaria. El trabajo, el hábito del silencio, los olores, las enfermedades, las perversiones, los suicidios, las sanciones, los servicios, son todos aspectos insoslayables para comprender cómo funciona efectivamente el nuevo dispositivo punitivo/corrector (PETIT 1990, p. 469).

Claude Petitfrère, historiador de la revolución francesa, es autor de otra reseña sobre el libro de Petit. Al igual que Marais y Léonard, considera que Petit ha concretado una gran labor de síntesis de los mayores aportes en la historia de la prisión. El interés esencial de Ces peines obscures, sostiene Petitfrère, es el haber insertado el sistema penitenciario del siglo XVIII en la lógica global de la sociedad burguesa, el haber mostrado cómo, a partir de los generosos proyectos reformadores de la Ilustración, se produjo un instrumento de eliminación menos de criminales "profesionales" que de los elementos más desprotegidos de la sociedad, al servicio de la gran empresa de control de las clases populares por las élites (PETITFRÈRE 1990, p. 120). Esto no es sino una ampliación de la segunda tesis de Vigilar y castigar, según el análisis de Brodeur. Repleto de referencias documentales y bibliográficas, y firmemente asentado en algunas de las propuestas de Foucault, el libro de Petit habrá satisfecho completamente las expectativas del criminólogo canadiense.

\section{Reflexiones finales: la historia de la prisión y la necesidad de una renovación}

Vigilar y castigar, por su característica irreverencia y desatención de los métodos y las formas establecidas, generó lo que en este trabajo hemos denominado la "reacción historiográfica". Tal mote, sin embargo, requiere ser 
matizado ya que ciertas observaciones de Léonard hacían referencia a algunas de las formas más innovadoras de la historiografía de los 70': recordemos las críticas por la falta de empleo de los resultados de las historias especializadas (de la educación, del trabajo, de la medicina, etc.) o por la exagerada racionalización o pasividad que Foucault atribuye al cuerpo social, crítica que podría leerse en sintonía con la teoría de resistencia cotidiana, en formulación por James C. Scott por esos años.

No obstante, de acuerdo a otras críticas efectuadas por Léonard, Agulhon y Brodeur y más tarde los mismos Perrot, Ignatieff y Petit, podría decirse que se trató de una respuesta conservadora, puesto que buscaba resguardar, frente al sacudón foucaultiano, las herramientas y el métier del historiador.

El oficio de historiar incluía, señalaron, algunas operaciones insoslayables como trabajar con documentación especializada, fuentes primarias, armar un estado de la cuestión que tenga en cuenta los avances sobre el tema, referirse con claridad a los actores en cuestión, etc. El ingrato lugar tomado por Léonard, dada la popularidad alcanzada por Foucault en los sectores más progresistas de la academia, implicó defender un conservadurismo de oficio, iniciando una serie de objeciones a Vigilar y castigar que fueron rápidamente olvidadas por el gran público pero que se fueron refrendando en el ámbito historiográfico a medida que otros historiadores publicaban sus investigaciones sobre la prisión. Es el caso de Petit en Francia, Ignatieff en Canadá o Lila Caimari en la Argentina, por sólo citar unos pocos entre la gran cantidad de autores que han historiado la prisión desde entonces a nivel internacional.

No obstante, más allá de las debilidades señaladas, los historiadores de la cárcel, de Petit a Caimari, reconocen hasta hoy el valor del aporte foucaultiano. En una reflexión sobre su historia de la Penitenciaría de Buenos Aires, Caimari sostuvo que, aunque el trabajo con la documentación carcelaria la había alejado de las hipótesis de Vigilary castigar, aquella obra produjo una suerte de revolución conceptual. Su originalidad no estaba en lo que dijo sobre la prisión sino en la matriz de su planteo, que revirtió los términos de las aproximaciones conocidas a estas instituciones. En vez de trabajar yendo de los contextos sociales hacia las maquinarias institucionales, Foucault invirtió el recorrido, haciendo foco en el corazón mismo de las instituciones (CAIMARI 2005, p. 7). Y eso fue captado también por Petit quien, además de ampliar algunas de las hipótesis de Foucault y proceder con el más refinado aparato erudito (empleando una grande y diversa cantidad de fuentes), sintetizó en su tesis doctoral los avances que se habían producido después de Vigilar y castigar.

Por todo eso, en el ámbito de los historiadores franceses, se recibió con mayor aceptación a Ces peines obscures, ya que constituía una forma de integrar los aportes de Foucault con la evidencia histórica disponible y los trabajos posteriores. El sociólogo Philippe Robert, en una reseña publicada en Annales, sostuvo que Petit había llevado a cabo con éxito el duro trabajo de poner a prueba las hipótesis de los trabajos de la "primera ola posfoucaultiana" producidos entre las décadas de 1970 y 1980. Asimismo, según Robert, la periodización de Petit se convirtió en la más convincente hasta el momento, 
superando a la de la historiadora norteamericana Patricia O'Brien (O' BRIEN 1982) ya que se enfocaba en el período clave que transcurre entre los últimos años de la monarquía absolutista y la caída del Imperio.

Ces peines obscures demostró, con mayor énfasis que cualquier otro trabajo, que la prisión francesa del siglo XIX, como institución "regeneradora" a través del trabajo, fue una empresa semi-privada. Emprendedores particulares se encargaban de la organización del trabajo al interior de las cárceles y de las "cantinas", donde los presos podían mejorar sus pobres raciones. Ese carácter semi-privado fue desapareciendo a lo largo del siglo XIX a medida que las cárceles fueron profesionalizándose. Aquellos que querían tratar a la prisión de manera científica favorecieron el cambio, aunque las querellas sobre el encierro celular dificultarían el proceso y sólo se lo resolvería de un modo pragmático. El Estado francés no pudo -o no quiso- pagar el costoso encierro celular.

Otro de los principales aportes de la obra de Petit fue ampliar y demostrar, mediante un minucioso examen de los distintos tipos de cárceles francesas, una de las tesis de Vigilar y castigar: que el fracaso de la prisión francesa como elemento regenerador no implicó su desaparición porque fue acompañada de un éxito como forma de administrar la delincuencia y la marginalidad, productos del "siglo del progreso" (PETIT 1990, p. 9).

Hasta aquí hemos visto el beneplácito con el cual los historiadores recibieron el trabajo de Petit. Sin embargo, de ese reconocimiento gremial -incomparable con el reconocimiento interdisciplinario del aporte de Foucault- surgen algunos interrogantes en vistas de lo sucedido en los años que siguieron a la publicación de Ces peines obscures. La obra de Petit no se multiplicó en más trabajos sino que fue una suerte de culminación de los años dorados de la historia penitenciaria. Después de su publicación, lentamente fue disminuyendo el espacio de la historia de las cárceles en el mercado editorial y hasta en los mismos circuitos académicos. Petit tuvo a su cargo una compilación de importancia sobre el tema en 1991 y luego hubo que esperar a 1996 -vigésimo aniversario de Vigilar y castigar- para que las editoriales y las universidades dedicaran espacios a las cárceles del pasado (PETIT 1996). De esta manera, la década de 1990 se acabó sin mayores novedades en el área $y$, ya en el naciente tercer milenio, los protagonistas continuaron siendo los mismos que habían participado de los debates en los '70: Petit, Perrot, Zysberg, Pierre, entre otros (ARTIERES 2010; PETIT 2002; PERROT; PETIT 2002). Con su retiro, la historia de la penalidad volvía a ser patrimonio de los sociólogos, herederos del legado de Durkheim.

Curiosamente había sido un filósofo quien transitoriamente les había arrebatado la cárcel como objeto de estudio para que los historiadores tomaran la posta. Desde 1975 y por un cuarto de siglo la investigación sobre la penalidad francesa fue de los historiadores. Podría decirse que Vigilar y castigar cristalizó, de alguna manera, en Ces peines obscures. Cabe preguntarse por qué el trabajo de Petit, si había superado a su mentor, no produjo sus propios discípulos, por qué el tema acabó diluyéndose en la agenda historiográfica.

De lo visto hasta aquí, es posible arriesgar que se debió a una cuestión de método, así como se le había señalado en su momento a Foucault. Petit 
empleó exhaustivamente el recurso del análisis histórico de las fuentes a nivel nacional pero no realizó una renovación en su forma de acercamiento al tema. No propuso un nuevo modo de abordar la historia de la prisión sino que $-y$ no es tarea menor- contrastó lo trabajado hasta entonces con la evidencia histórica disponible. Es probable entonces que el decaimiento del tema y la falta de continuadores del trabajo de Petit hayan provenido de la falta de innovación en su enfoque.

Es innegable que se trata de una obra minuciosa y exhaustiva, pero justamente por eso no abrió nuevos espacios para dar algún giro interpretativo encomendable a sus discípulos. En Ces peines obscures se respeta el métier del historiador, el empleo de recursos documentales y de bibliografía especializada pero se descuida la incorporación de los aportes de otras disciplinas. Si en un primer momento, en los años 70' y 80' la "reacción" permitió producir una historia de la prisión más completa a partir del impulso de Vigilar y castigar, es probable que hoy la solución para revitalizar esa historia un tanto marginada en los últimos años sea una renovación a través de enfoques interdisciplinarios. Un acercamiento hacia las disciplinas vecinas, como la sociología o la arqueología urbana, que permitan ver de nuevas maneras a una documentación tan vasta y diversa como la del universo penal de los siglos XIX y XX. Si efectivamente se produjo un declive en la historiografía penitenciaria francesa, éste pudo haber sido causado precisamente por los aspectos conservadores de una respuesta que, inicialmente, tuvo éxito al reforzar el método historiográfico, pero, con el

72 pasar de los años, no pudo renovar los acercamientos al tema.

\section{Referencias bibliográficas}

ARTIERES, Philippe et al. Surveiller et punir de Michel Foucault: regards critiques 1975-1979. Caen: PUC, 2010

BRODEUR, Jean-Paul. Surveiller et punir. Criminologie, v. 9, n. 1-2, p. 196218, 1976.

CAIMARI, Lila. Usos de Foucault en la investigación histórica. Victoria: Universidad de San Andrés, Documento de Trabajo n 18, 2005. Disponible en: http://live.v1.udesa.edu.ar/files/EscEdu/DT/DT18-CAIMARI.PDF.

DEYON, Pierre. Le temps des prisons: essai sur I'histoire de la délinquance et des origines du système pénitentiaire. Lille: Editions Universitaires, 1975.

DHAUSSY, Catherine. Utopie et démocratie humanitaire aux États-Unis et en France entre 1830 et 1848: comparaison et étude d'interactions. Tesis (Doctorado en Historia) Universidad de Paris 13, Paris, 2005.

DURKHEIM, Émile. La división del trabajo social. Madrid: Akal, 2001.

FOUCAULT, Michel. Surveiller et punir. Naissance de la prison. Paris: Gallimard, 1975.

GARLAND, David. Castigo y sociedad moderna. Un estudio de teoría social. México: Siglo XXI, 1999. 
IGNATIEFF, Michael. Historiographie critique du système pénitentiaire. In: PETIT, Jacques Guy (dir.). Les prisons, le bagne et l'histoire. Paris: Méridiens, p. 9-17, 1984.

LEONARD, Jaques ; FOUCAULT, Michel. La imposible prisión: debate con Michel Foucault. Barcelona: Anagrama, 1982. ; PETIT, Jacques-Guy (dir.) . La prison, le bagne et I'historie. Annales de Bretagne et des pays de I'Ouest, v. 92, n. 2, p. 226-227, 1985.

MARAIS, Jean-Luc. Jacques-Guy Petit, Ces peines obscures. Annales de Bretagne et des pays de l'Ouest, v. 97, n. 4, p. 547-548, 1990.

O'BRIEN, Patricia. The Promise of Punishment: Prisons in Nineteeth-Century France. Princeton: PUP, 1982.

PERROT, Michelle. Délinquance et système pénitentiaire en France au XIXe siècle. Annales - Économies, Sociétés, Civilisations, v 30, n. 1, p. 67-91, 1975.

(dir.) L'Impossible prison : recherches sur le système pénitentiaire au XIXe siècle. Paris: Seuil, 1980.

; PETIT, Jacques Guy et al. Femmes et justice pénale XIXe-XXe siècles. Rennes: PUR, 2002.

PETIT, Jacques Guy. La vie et la pensée de D. Bonhoeffer. Carmel. Revue d'histoire de la spiritualité, v 1, p. 42-45, 1969.

. Monchanin et I'homme universel. Orient-Occident, v III, n 6, p. 2-16, 1970a.

. Diálogo entre el budismo zen y el Occidente. Temas, n 47, p. 16-23, 1970b.

Le système pénitentiaire au XIXe siècle: problématique et recherches. Annales de Bretagne et des pays de l'Ouest, v. 88, n. 3, p. 363-368, 1981.

Mystique et intelligence critique: la jeunesse de J. Monchanin. Paris: Beauchesne, 1983.

Ces peines obscures: la prison pénale en France, 1780-1875. Paris: Fayard, 1990.

- Les historiens de la prison et Michel Foucault. Sociétés \& Représentations, n. 3, p. 157-170, 1996.

; SALVATORE, Ricardo D., AGUIRRE, Carlos Aguirre (eds.). The Birth of the Penitentiary in Latin America. Essays on Criminology, Prison Reform and Social Control, 1830-1940. Crime, Histoire \& Sociétés, v. 7, n. 2, p. 133-135, 2002.

; (dir.). Les prisons, le bagne et I’histoire. Paris: Méridiens, 1984.

et al. Histoire des prisons en France (1789-2000). Le système pénitentiaire et les bagnes d'outre-mer. Toulouse: Éditions Privat, 2002 
PETITFRERE, Claude. Jacques-Guy Petit, Ces peines obscures, Annales historiques de la Révolution française, v. 283, n. 1, p. 117-120, 1990. ROBERT, Philippe. Jacques-Guy Petit, Ces peines obscures. Annales Économies, Sociétés, Civilisations, v. 45, n. 5, p. 1260-1262, 1990.

ROTHMAN, David J. The discovery of the asylum: social order and disorder in the new republic. Boston: Little Brown, 1971.

WEBER, Max. Economía y sociedad. México: FCE, 1964.

ZYSBERG, André. Pierre Deyon, Le temps des prisons. Essai sur l'histoire de la délinquance et les origines du système pénitentiaire; Michel Foucault, Surveiller et punir. Naissance de la prison, Annales - Économies, Sociétés, Civilisations, v. 31, n. 1, p. 168-175, 1976. 